\title{
ANÁLISE DA ABORDAGEM DA REVOLUCÃO RUSSA NOS LIVROS DIDÁTICOS ATUAIS
}

\section{Cristiane Aparecida Ribeiro' Ana Enedi Prince ${ }^{2}$}

Resumo: Esse artigo tem como objetivo proporcionar uma reflexão acerca da metodologia utilizada nos livros didáticos ao enfocar a Revolução Russa. Considerando que esse tema é relevante para a compreensão da sociedade contemporânea, se faz necessário que ele seja trabalhado com profundidade, de maneira contextualizada, de forma que ocorra a sistematização do processo ensino e aprendizagem. A ideologia implícita nesses conteúdos deve ser analisada e compreendida pelos discentes, proporcionando a sua reflexão para que compreendam esse importante acontecimento histórico na sua totalidade Palavras-chave: Revolução Russa; Livro didático; Ideologia.

\footnotetext{
${ }^{1}$ História/Universidade do Vale do Paraíba, Brasil. E-mail: car7517@gmail.com.

2 História/Universidade do Vale do Paraíba, Brasil. E-mail: prince@univap.br.
} 